\title{
A intoxicação por samambaia em bovinos criados no Estado do Paraná
}

\author{
Bracken fern poisoning to cattle raised in Parana State, Brazil.
}

\author{
Wilmar Sachetin Marçal ${ }^{1}$
}

\begin{abstract}
Resumo
O autor apresenta uma revisão sobre a intoxicação por samambaia (Pteridium aquilinum, L. Kuhn), em bovinos, criados no estado do Paraná. Esta planta representa enormes prejuízos aos criadores no estado e está se disseminando rapidamente, tornando-se a planta tóxica de maiores consequiências negativas à saúde dos bovinos, havendo condições ambientais e climáticas favorecedoras de sua proliferação nas pastagens paranaenses.
\end{abstract}

Palavras-chave: Bovinos, intoxicação, samambaia, Pteridium aquilinum.

\begin{abstract}
The author presents a revision about bracken fern (Pteridium aquilinum, L. Kuhn), in cattle, raised in the state of the Paraná. This toxic plant represents huge damages to the creators in the state and is being disseminated quickly, becoming the toxic plant of negative consequences to the health of the cattle. The author also describe climatic and environmental conditions about proliferation of Bracken fern in the Parana state, Brazil.
\end{abstract}

Key words: Cattle, toxic, bracken fern, Pteridium aquilinum.

\section{Introdução}

A Pteridium aquilinum é um dos vegetais tóxicos mais preocupantes em vários países do mundo, incluindo o Brasil. Por causar enfermidades que acometem rebanhos de bovinos (NIERO et al., 1991; TOKARNIA; DOBEREINER; PEIXOTO, 2000; MARÇAL et al., 2001), tem sido considerada uma planta tóxica que causa grandes prejuízos à pecuária bovina paranaense, ocorrendo em 105 municípios (POLACK, 1990), dos 399 existentes no Estado (FERREIRA, 1996). Embora em algumas fazendas as pastagens sejam renovadas, ainda assim a samambaia persiste, em proporções que variam de, no mínimo, brotos quase imperceptíveis a arbustos bem desenvolvidos (OLIVEIRA; MATSUMOTO; PRIMAVESI, 1998).

A existência de um número variado de trabalhos científicos a respeito da Pteridium aquilinum e suas implicações na saúde de bovinos é fato incontestável. Existem diversos trabalhos demonstrando a existência das manifestações clínicas da toxidez e suas restritas ligações com a samambaia. Relatos de surtos afetando rebanhos de bovinos no estado do Paraná já foram observados por Basile, Gaste e Reis (1981), Polack (1990), Niero et al. (1991), Oliveira, Matsumoto e Primavesi (1998), Marçal et al (2001) e Marçal et al. (2002).

\footnotetext{
1 Médico veterinário, Professor Associado do Departamento de Clínicas Veterinárias, Centro de Ciências Agrárias, Universidade Estadual de Londrina, Caixa Postal 6001, cep: 86051-970, Londrina - PR. E-mail: wilmar@uel.br
} 


\section{Considerações Sobre a Planta}

A Pteridium aquilinum, popularmente chamada de samambaia do campo ou simplesmente samambaia, é uma planta perene, rizomatosa, herbácea, ereta e ramificada, medindo entre 50 a $180 \mathrm{~cm}$ de altura (TOKARNIA; DOBEREINER; SILVA, 1979).

Os estudiosos destacam que a samambaia é uma planta cosmopolita de todas as regiões tropicais e temperadas (SEHNEM, 1972). Com exceção feita às plantas daninhas, é possivelmente a mais ampla e distribuída das plantas vasculares. Segundo Taylor (1989) a samambaia é encontrada em todos os continentes, exceto no Antártico, sendo considerada como a maior praga do reino vegetal e listada entre as cinco espécies vegetais de maior ocorrência na Terra. Conforme Evans (1984 apud FRANÇA; TOKARNIA; PEIXOTO, 2002) essa planta tem sido registrada desde o período mesozóico, há cerca de 150 milhões de anos.

Trata-se de um vegetal de característica invasora, sendo bastante freqüente em solos ácidos, arenosos e de baixa fertilidade. Infesta campos, matas ciliares, capoeiras, beiras de matos e de estradas. $\mathrm{Na}$ Finlândia, calcula-se que clones individuais da planta existem há mais de 650 anos e que a remoção da cobertura florestal cria habitat ideal para a invasão da samambaia (OINONEN, 1967), mantendo-se exuberante em ambientes onde há pouca competição (POLACK, 1990).

Do ponto de vista botânico, o gênero Pteridium é considerado monotípico e a única espécie é a aquilinum. Entretanto, nessa espécie há duas subespécies, aquilinum e caudatum, sendo estas compostas por diversas variedades geográficas (TAYLOR, 1989). Na América do Sul registra-se, principalmente, a ocorrência de Pteridium aquilinum sub-espécie caudatum, variedade caudatum (TRYON, 1941). No Brasil a presença da Pteridium aquilinum já foi registrada em praticamente todos os estados (LORENZI, 1982), tendo sido identificada a variedade arachnoideum (TOKARNIA; DOBEREINER; PEIXOTO, 2000).

\section{Princípios Tóxicos da Samambaia}

Todas as partes da samambaia contém os princípios tóxicos em forma ativa, sendo o broto a porção mais tóxica de suas partes aéreas e o rizoma a parte da planta que possui maior atividade carcinogênica (HIRONO et al., 1973). A planta, mesmo quando dessecada, também conserva a toxidez por muito tempo (TOKARNIA; DOBEREINER; SILVA, 1979). A brotação que surge após as queimadas ou geadas é muito temida e perigosa, pois concentra uma grande quantidade dos princípios tóxicos da planta. Esse aspecto indica que a planta torna-se ainda mais perigosa para os bovinos criados extensivamente, determinando quadros agudos de toxidez (Marçal, 2000), principalmente quando há superlotação de pastagens (PARKER; MCCREA 1965).

Conforme destaca Hopkins (1986), a planta possui diferentes princípios tóxicos com ação carcinogênica, entre os quais: tanino; quercetina; ácido chiquímico; prumasina; ptaquilosideo; aquilideo A e canferol. Segundo Polack (1990) muitos estudos vem sendo conduzidos para se conhecer outros princípios tóxicos da planta, já tendo ocorrido o isolamento de diversos ácidos orgânicos como o ácido dicafeiltartárico (chicoric acid), pelo menos cinco flavonóides, perto de 30 pterosina-sesquiterpenos e, também, polissacarídeos, glicosídios, astragalinas, isoquercetina, catecolaminas e pteraquilina. Sobre o ptaquilosídeo, Riet-Correa, Méndez e Schild (1993) afirmam se tratar de um glicosídeo norsesquiterpeno que contribui significativamente para a ação mutagênica e carcinogênica da Pteridium aquilinum. Clarke e Clarke (1975), Tokarnia, Dobereiner e Silva (1979) e Tokarnia, Dobereiner e Peixoto (2000), mencionam ainda a existência da tiaminase, muito representativa toxicologicamente aos eqüinos, determinando quadro clínico neurológico, embora a toxidez naquela espécie seja rara de ocorrer nas condições brasileiras (MARÇAL; CAMPOS NETO, 1996; MARÇAL, 2000). Já em 1942 Goetze (apud REICHMANN, 1975), supunha existir na samambaia além da tiaminase, um veneno vascular 
causador da diátese hemorrágica, responsável por manifestações agudas de quadros tóxicos.

Ainda sobre os princípios tóxicos, Singh, Joshi e Ray (1980) destacam que, num experimento com bovinos de 2 a 4 anos, animais com manifestação clínica de hematúria, apresentaram valores aumentados de uma mucoproteina e do ácido siálico. Segundo os autores, essas substâncias possuem forte ligação com o crescimento neoplásico das células da bexiga, responsável pela hematúria naqueles bovinos.

\section{Condições para Intoxicar}

Embora a planta não seja palatável, determinadas condições favorecem sua ingestão pelos bovinos. Em épocas de escassez alimentar, a fome constitui a primeira causa básica de ingestão da samambaia pelos bovinos. Isto normalmente ocorre em estações secas, pois a planta suporta bem o período sem chuvas, possibilitando sua procura pelos animais (MARÇAL, 1990). Segundo Tokarnia, Dobereiner e Peixoto (2000), os bovinos que ingerem a samambaia acabam "viciados na planta", por causa das ingestões repetidas e compulsivas, caracterizando-se assim o vício como segundo fator para intoxicar.

O terceiro fator que possibilita a procura dos animais pela planta é a carência de pastagem fibrosa (TOKARNIA; DOBEREINER; SILVA, 1979; MARÇAL, 1990). Como a samambaia costuma se desenvolver e atingir boa altura, os bovinos suprem a necessidade de fibra, comendo os caules e folhas longas que a planta normalmente possui (TOKARNIA; DOBEREINER; SILVA., 1979; TOKARNIA; DOBEREINER; PEIXOTO, 2000).

Por fim, os bovinos eventualmente se intoxicam pelo fornecimento de feno contaminado que contenha a samambaia, o que pode ocorrer com animais semiconfinados (MARÇAL; GASTE; BALARIN, 1991; TOKARNIA; DOBEREINER; PEIXOTO, 2000).

A intoxicação pela planta nos eqüinos ocorre provavelmente quando os animais ingerem aproximadamente $10 \mathrm{~g} / \mathrm{Kg}$ num espaço de 30 a 40 dias, embora esses animais não tenham hábito de procurar a planta, porque possuem o apetite mais seletivo que os bovinos. Entretanto, as causas apresentadas como condições de favorecimento da intoxicação na espécie bovina podem ser aplicadas aos eqüinos, particularmente pela fome e pela contaminação no feno (MARÇAL, 2000).

\section{Manifestação Sazonal}

Com relação a manifestação sazonal, Musca et al. (1997), trabalhando com bovinos na Romênia, detectaram uma maior incidência de manifestações clínicas nas estações do verão e outono. No Brasil, Tokarnia, Dobereiner e Canella (1967), ao presenciarem um surto de intoxicação pela samambaia, associaram a escassez de pastagens no inverno e a presença da planta na propriedade rural com a ocorrência do episódio.

Marçal (2000) destaca que em várias fazendas no sudeste e sul do Brasil, ocorre uma maior manifestação clínica de surtos agudos na época do inverno, devido a escassez das pastagens e pelo fato da samambaia suportar bem a seca. Segundo o autor, a planta tem se disseminado muito no estado do Paraná porque encontra condições edafoclimáticas favoráveis para ocupar terras não mecanizáveis, mas que servem como pastagem ao rebanho bovino.

\section{Formas Clínicas da Intoxicação em Bovinos}

A intoxicação pela samambaia nos bovinos pode se manifestar de forma superaguda, aguda, subaguda e crônica (SOUZA; GRAÇA, 1993), sendo que os quadros agudos ocorrem pela ingestão da planta em quantidades diárias superiores a $10 \mathrm{~g} / \mathrm{kg}$ de peso por períodos que variam de 3 semanas a poucos meses (GIBBONS, 1956). A forma crônica de manifestação tóxica caracteriza-se pela Hematúria Enzoótica e pela formação de carcinomas epidermóides no trato digestivo superior, necessitando que os bovinos consumam uma quantidade maior da planta por longos períodos (CAMPOS NETO; BARROS; BICUDO, 
1975; TOKARNIA; DOBEREINER; SILVA., 1979; TOKARNIA; DOBEREINER; PEIXOTO, 2000). Nos quadros tóxicos não há predisposição por raça (PAMUKCU; PRICE; BRYAN, 1976), ou mesmo sexo (HOPKINS, 1986). No Brasil, os primeiros casos de hematúria enzoótica dos bovinos foram relatados por Bueno (1953) como papilomatose faringeana e por Lacaz (1954) nas observações de cistite com presença de hemácias na urina.

Segundo Yamane, Hayashi e Saku. (1975), na intoxicação aguda pela samambaia em bovinos, há também um aumento de fragilidade capilar e no tempo de sangramento, e uma diminuição na retração do coágulo, que pode ser evidenciado com base na trombocitopenia e no aumento do fibrinogênio. Hayashi (1981) relatou que, hematologicamente, bovinos intoxicados, revelam depressão da atividade da medula óssea com trombocitopenia e leucopenia e que a diminuição na contagem plaquetária está associada à diminuição na contagem de megacariócitos, comprovada pela biópsia de medula óssea. Pelas observações de Durão, Ferreira e Cabral (1995), a intoxicação aguda é caracterizada por uma síndrome hemorrágica em quase todas as vísceras, levando os animais a óbito em torno de 12 a 72 horas após o aparecimento dos primeiros sinais clínicos. Esta forma clínica da doença é popularmente conhecida por "suor de sangue" (MARÇAL, 1990; NIERO et al., 1991), referindo-se a uma manifestação clínica de hematidrose (MARÇAL, 2000).

A segunda forma de manifestação da intoxicação é conhecida por fase de hematúria enzoótica dos bovinos. Ela foi verificada e classificada quando se forneceu a planta aos bovinos em quantidades inferiores a $10 \mathrm{~g} / \mathrm{Kg}$ durante um ou mais anos (ROSENBERGER; HEESCHEN, 1960; PAMUKCU; GOKSOY; PRICE, 1967; MUELLER et al., 1975; MAXIE, 1993). As principais características desta fase são evolução crônica, incontinência urinária com hematúria intermitente e emaciação. Ocorre perda de sangue sem reposição pela medula (anemia aplástica), podendo acometer vacas prenhes e causar abortamento (MARÇAL et al., 2001).
A terceira forma de manifestação foi classificada ofertando-se quantidades muito pequenas aos bovinos (menos que $10 \mathrm{~g} / \mathrm{kg}$ ), porém por vários anos. Esta fase também tem característica crônica, sendo determinada pela formação de carcinomas epidermóides nas vias digestivas superiores (DOBEREINER; TOKARNIA; CANELLA, 1967; TOKARNIA; DOBEREINER; SILVA, 1979). Há suposições populares ou crendices de que os processos neoplásicos no aparelho digestivo superior sejam devido a ingestão das folhas espinhentas do "caraguatá", nome popular do vegetal Aloe humilis (POLACK, 1990), pertencente à família das Bromeliaceas (CORREA, 1931). Quando essas neoformações se localizam na faringe, devido ao seu aspecto macroscópico, chama-se popularmente de "figueira da goela" ou "favo". Os bovinos acometidos demonstram emagrecimento progressivo por dificuldade de deglutição, tosse, "ronquidão" ou "ronqueira", dispnéia com demasiado cansaço, isolando-se do rebanho. Costuma acometer bovinos com mais de cinco anos de idade. Tem sido sugerido que há uma interação entre o vírus da papilomatose e a ingestão de substâncias cancerígenas de Pteridium aquilinum no desenvolvimento desses carcinomas, ou seja, a Pteridium aquilinum teria um efeito imunodepressivo que limita a eficiência da resposta imunológica do animal frente a vírus capazes de produzir tumores (JARRETT, 1978; CAMPO et al., 1980; FENWICK, 1988; MOURA, 1989; BARKER; VAN DREUMEL; PALMER, 1993).

É preciso ressaltar, entretanto, que muitos ensaios a campo vem demonstrando que as manifestações de hematúria e o "caraguatá" estão surgindo em bovinos mais jovens, machos e fêmeas, alguns com somente 18 meses de idade, acarretando mais prejuízos aos criadores (MARÇAL et al., 2001). Destas três formas clínicas classicamente conhecidas, a incidência maior de casos refere-se à hematúria enzoótica dos bovinos, e a menor, aos casos de carcinoma epidermóides do trato digestivo superior. Os casos agudos embora ocorram com menor incidência ainda, sempre representam muitos 
óbitos de bovinos. Porém, em todas elas os impactos econômicos são muito significativos.

\section{Relatos no Estado do Paraná}

Basile, Gaste e Reis (1981) relataram a ocorrência da forma aguda de intoxicação em 16 bovinos na região de Londrina, estado do Paraná, onde os óbitos de todos os animais ocorreram entre um a três dias após o inicio dos sintomas clínicos, sobretudo por diátese hemorrágica. Niero et al. (1991), relataram um surto de intoxicação aguda pela samambaia em Tamarana, estado do Paraná. Na oportunidade, final de inverno de 1990, 42 machos e 5 fêmeas da raça nelore, com faixa etária de 12 a 36 meses de vida, vieram a óbito. Os principais sintomas observados pelos autores, em alguns animais antes da morte e na necrópsia, foram hematidrose, epistaxis, hemorragias nas mucosas e serosas, petéquias e sufusões na pleura e peritonio visceral, nos intestinos e rúmen.

Ainda com relação aos episódios de intoxicação aguda pela samambaia, Polack (1990), observou, em alguns animais do rebanho bovino paranaense, que os quadros agudos estavam associados à intensidade de ocorrência da Pteridium aquilinum nas pastagens das fazendas, sendo que o maior número de mortes ocorreu em municípios onde a intensidade da planta foi considerada de moderada a alta.

Oliveira, Matsumoto e Primavesi (1998), em pesquisa requisitada por pecuaristas da região nordeste do Paraná, verificaram pela anamnese, nos municípios de Santo Antônio da Platina, Ibaiti e Arapoti, que o problema de intoxicação pela planta era mais freqüente nos animais de primeira cria, na faixa etária de 4 a 5 anos. Os bovinos apresentavam urina com coloração avermelhada, emagrecimento progressivo e prostração, com quadro clínico irreversível, culminando com óbito no período de 10 a 60 dias.

Marçal et al. (2001) descreveram a ocorrência de um surto de intoxicação aguda pela samambaia em bovinos, criados numa propriedade rural localizada no município de Reserva, estado do Paraná.
Um total de 25 animais foram a óbito e a ocorrência da intoxicação teve, muito provavelmente, relação direta com as freqüentes e acentuadas geadas ocorridas no mês de julho de 2000. Além do relato clínico, os autores apresentaram considerações a respeito da proliferação da samambaia no Paraná, destacando condições ambientais e climáticas favorecedoras dessa disseminação, bem como os prejuízos à pecuária e as conseqüências da presença desse vegetal tóxico nas pastagens paranaenses.

Novo surto de intoxicação aguda foi descrito por Marçal et al. (2002). Bovinos da raça Aberdeen angus, criados numa propriedade rural localizada no município de Ortigueira, estado do Paraná foram vitimados pela planta. Um total de 14 animais foram a óbito e a ocorrência da doença foi devida a superlotação de animais em piquetes, que tornaram as pastagens cultivadas muito baixas, favorecendo a procura pela samambaia, que mantinha-se viçosa e atraente ao consumo, o que possibilitou uma ingestão de grande quantidade em curto espaço de tempo pelos bovinos.

\section{Diagnóstico}

Quando ocorrem as manifestações clínicas da intoxicação pela samambaia em bovinos, a primeira conduta ao diagnóstico é constatar a existência da planta na propriedade.

Nas situações crônicas, como hematúria e carcinoma, atendimentos clínicos podem ser feitos em propriedades onde não existe a samambaia. É necessário, então, uma anamnese investigativa, bem como a checagem da planta na fazenda de origem dos animais.

Marçal (2000) alertou para questões litigiosas na compra de animais em leilões e transações comercias, já que a manifestação clínica, sobretudo de hematúria, pode ocorrer após a chegada dos bovinos na nova propriedade rural.

Importante conduta a ser considerada em propriedade com infestação da planta é colher a urina dos animais e submete-la à pesquisa laboratorial de 
microhematúria, o que pode significar anteceder o diagnóstico de hematúria e mudar os animais de pasto. Além disso, quando for o caso, necropsiar os bovinos que morreram, para se concluir pela presença de evidências da toxidez determinada pela samambaia. Em algumas circunstâncias, um animal doente pode ser sacrificado para "representar" o rebanho e confirmar a intoxicação.

\section{Diagnóstico Diferencial}

Embora as formas clínicas sejam bem conhecidas, é importante considerar enfermidades com sintomatologia semelhante para o diagnóstico diferencial. Na fase aguda ou de diátese hemorrágica deve-se levar em conta a Pasteurelose (TOKARNIA; DOBEREINER; SILVA, 1979), Babesiose, Anaplasmose, Leptospirose, intoxicação por Crotalaria sp, intoxicação por trevo doce mofado, Hemoglobinúria bacilar (POLACK, 1990), Carbúnculo hemático e a síndrome produzida por irradiação ionizante (HAGAN, 1952; SIPPEL, 1952; EVANS; EVANS; HUGHES, 1954).

A forma de hematúria enzoótica precisa ser diferenciada da hemoglobinúria (TOKARNIA; DOBEREINER; SILVA, 1979), bastando colher a urina, na própria fazenda, e verificar a formação de sedimento, o que não ocorre quando se tem hemoglobinúria por hemoparasitose ou por outra causa (MARÇAL, 2000).

A forma de carcinoma epidermóide do trato digestivo superior precisa ser diferenciada da tuberculose e actinobacilose (TOKARNIA; DOBEREINER; SILVA, 1979), enfermidades com características de emagrecimento progressivo e dificuldade de deglutição alimentar (TOKARNIA; DOBEREINER; CANELLA, 1969; MARÇAL, 1990).

\section{Achados de Necrópsia}

Durante a necrópsia de bovinos com quadro agudo de intoxicação pode-se perceber lesões hemorrágicas do tecido celular subcutâneo, hemorragias no baço, intestino e bexiga, além de úlceras nas mucosas (TOKARNIA; DOBEREINER; SILVA, 1979; BASILE; GASTE; REIS, 1981; DURÃO; FERREIRA; CABRAL, 1995; MARÇAL et al., 2001). O sistema digestivo mostra edema e vários pontos hemorrágicos, bem como a presença de fragmentos da samambaia no interior do rúmen (NIERO et al., 1991; MARÇAL et al., 2001). Nesta forma a histopatologia revela rarefação do tecido hematopoiético na medula óssea, com acentuada diminuição do número de células, depressão da série megacariocítica e granulocítica (EVANS; EVANS; HUGHES, 1954; TOKARNIA; DOREREINER; CANELLA, 1967; TOKARNIA; DOBEREINER; SILVA, 1979; NIERO et al., 1991; TOKARNIA; DOBEREINER; PEIXOTO, 2000). As alterações mais significativas ao exame hematológico são trombocitopenia e leucopenia (EVANS; EVANS; HUGHERS, 1954; EVANS; HOWELL, 1962; NIERO et al., 1991; MARÇAL; CAMPOS NETO, 1996; MARÇAL et al., 2001).

$\mathrm{Na}$ hematúria enzoótica são visíveis os hemangiomas ou nódulos puntiformes na bexiga, às vezes do tamanho de um grão de ervilha, podendo atingir um diâmetro maior (MARÇAL, 2000).

No carcinoma epidermóide do trato digestivo superior, popular "caraguatá", observa-se formação nodular na região de orofaringe, com o tumor assumindo o aspecto de "couve-flor", atingindo importantes estruturas digestivas e respiratórias nos bovinos. A histopatologia revela que o tumor é carcinomatoso. A presença de papilomas no cárdia e esôfago não é um achado raro, tanto na hematúria como no carcinoma (TOKARNIA; DOBEREINER; SILVA, 1979; MARÇAL, 2000).

\section{Medidas Terapêuticas}

Não há terapia específica, pois a toxidez causada pela planta pode rapidamente matar os bovinos com quadros de diátese hemorrágica ou determinar 
situações crônicas irreversíveis da hematúria enzoótica e/ou "caraguatá". O que existe em termos terapêuticos, são medidas paliativas, embora muitas vezes não passem de tentativas (MARÇAL, 2000). Nesse sentido, foi realizado um estudo em propriedades rurais no estado do Paraná, testando a eficácia de alguns produtos na suspensão temporária da hematúria, sobretudo em vacas gestantes, através de um medicamento hemostático diretamente aplicado na bexiga. Os resultados permitiram considerar esse método terapêutico como importante auxílio para evitar-se o abortamento dos animais, diminuindo assim, prejuízos aos criadores de bovinos em áreas endêmicas (MARÇAL; GASTE; BALARIN, 1991).

No caso da hematúria enzoótica, Stober (1970) já mencionava que não se conhece tratamento eficaz e que a retirada dos animais dos pastos invadidos pela samambaia com adequada suplementação alimentar levam a uma lenta recuperação, desde que a enfermidade não esteja em estágio avançado, porém nunca a uma cura completa.

Há referência da utilização de produtos para estimular a medula óssea a produzir sangue, ação semelhante a alguns anabolizantes humanos. Dalton (apud BLOOD; HENDERSON; RADOSTITS, 1979), utilizou álcool DL-Batil com esse propósito, mas o teste foi realizado somente em um animal. Essa tentativa terapêutica nem sempre surte o efeito desejado (BLOOD; HENDERSON; RADOSTITS, 1979), sendo marcada mais pelo insucesso, pois não há tempo hábil para que a reposição sangüínea assegure a vida do animal enfermo, já que o número de plaquetas e leucócitos é baixo (MARÇAL, 1990). Além disso, é extremamente oneroso o uso desses tipos de medicamentos e nem sempre surtem o efeito esperado. Medicar os animais com sais de ferro também não é recomendado, pois a anemia não é ferropriva (MARÇAL, 1990; MARÇAL, 2000). Complexos vitamínicos que contenham vitamina $\mathrm{K}$ (anti-hemorrágica), bem como as transfusões sanguiíneas são inúteis, pois os princípios tóxicos continuam agindo no organismo dos animais, além do que, seria necessário um volume muito grande de reposição sangüínea para debelar o problema, o que a torna inviável economicamente (MARÇAL, 2000).

Alguns criadores no norte do estado do Paraná estão vacinando os bovinos contra hemoglobinúria bacilar, afirmando que as vacas param de urinar sangue. Entretanto, esta observação pode ser considerada também como um paliativo, pois a vacina não atua sobre o efeito tóxico causado pela samambaia. É provável que, como em toda vacinação, os bovinos tenham uma "melhora imunológica transitória”, mas não o suficiente para debelar a hematúria. Após alguns dias, o problema reincide.

\section{Medidas Preventivas}

Para o rebanho bovino é necessário e conveniente dedicar atenção especial à profilaxia, única medida que consegue limitar a enfermidade. Ela é realizada pela erradicação da samambaia nos pastos, arrancando a planta na época da rebrota. O êxito deste procedimento demora algum tempo, mas eliminar a planta ainda continua sendo o melhor procedimento para se acabar com as intoxicações (MARÇAL, 2000). No estado de São Paulo, segundo Marçal (1992), a Brachiaria decumbens disseminou-se muito na década de 90 , pois não é uma gramínea exigente quanto à questão de fertilidade do solo. Segundo o autor essa rápida disseminação foi responsável pela quase extinção da samambaia em muitas áreas que, no passado, sofreram com mortalidade de bovinos intoxicados pela planta.

Na questão da erradicação, melhores perspectivas podem surgir com aplicação da tecnologia agrícola, erradicando a samambaia por um cuidado intensivo do solo, com boas e completas adubações, calagem e formação de novas pastagens com qualidade. Se estas medidas não forem possíveis, recomenda-se a alternância de pastoreio entre pastos contaminados e limpos em períodos de vinte e um dias (REICHMANN, 1975). 
É extremamente importante que haja uma correta e contínua mineralização do gado em áreas onde a samambaia ainda não foi erradicada. A mineralização exerce uma importante ação preventiva, evitando tornar os animais imunodeprimidos e mais vulneráveis, condição propícia para que a planta acelere as manifestações tóxicas nos bovinos (MARÇAL, 2000).

Deve-se evitar a superpopulação de animais num mesmo pasto, pois com a pastagem sendo consumida rapidamente, os bovinos procuram a samambaia para suprir a fome. Alguns criadores adquirem animais em época de preço baixo da arroba e arrendam pastagens para recria. Normalmente as terras mais baratas para esta finalidade são aquelas onde há presença da planta, o que acaba determinando grandes perdas pela sua toxidez.

O desmatamento, destoca, degradação das pastagens e os roçados abandonados levam ao desequilíbrio ecológico, com variações climáticas indesejáveis, causando o empobrecimento do solo e favorecendo a proliferação da samambaia. Por essas razões, esses aspectos devem ser evitados (MARÇAL et al., 2001).

\section{Aspectos de Saúde Pública}

No homem há uma correlação positiva entre a ingestão do leite de vacas contaminado pelo ptaquilosídeo e a maior incidência de câncer no estômago (ALONSO-AMELOT et al., 1996). A toxina da planta já foi isolada no leite bovino, demonstrando que os bezerros que mamam o leite de vacas intoxicadas fecham o ciclo da doença e continuarão a ser doentes. Estudos também demonstraram a formação de tumores em ratos e camundongos alimentados com leite de vacas que consumiram samambaia. $\mathrm{O}$ consumo de leite de vacas intoxicadas deve ser rigorosamente evitado e comercializado. No Japão, há uma tradição em se consumir a samambaia, através de um prato conhecido por "warabi", considerado um alimento nacional, sendo, por outro lado, responsável por alta incidência de câncer de estômago no homem (HIRAYAMA, 1979).

Pela literatura consultada, não há ainda, conhecimento científico suficiente para condenar o consumo de carne dos bovinos acometidos pela enfermidade. Entretanto, alguns pesquisadores alertam que uma maior porcentagem de câncer de estômago no homem ocorre nas regiões onde existem vacas que se alimentam de samambaia (ALONSOAMELOT et al., 1996). Por estas conexões, é preciso evitar o consumo da carne como prevenção à saúde do homem, exemplo que ressalta, ainda mais, a importância dos conhecimentos da ciência veterinária e suas inúmeras contribuições para a saúde pública.

\section{Considerações Finais}

Em outros tempos, onde, apesar da existência da samambaia, haviam outras pastagens, nativas ou cultivadas, como alternativas atóxicas para a alimentação do gado, esta intoxicação tinha menor importância mas, ao longo dos anos, esse panorama vem mudando. A planta está se disseminando muito rapidamente, ocupando cada vez maiores áreas. Por isso, tornou-se alternativa de alimento ao gado em várias regiões do estado. Polack (1990), em pesquisa epidemiológica no estado do Paraná, já alertava para o fato de que a Pteridium aquilinum progrediu muito no estado, porque aliou a interferência universal e desinformada do homem com o meio ambiente, criando mais áreas desocupadas, sem respeitar as implicações ecológicas. O problema da difusão da samambaia, conforme destaca a mesma autora, foi claramente criado pelo próprio homem e, talvez apenas a restauração do equilíbrio ecológico natural asseguraria o seu controle. Lamentavelmente muitos surtos ainda irão surgir, pois isto demanda um longo prazo (PAGE, 1976). As observações de campo em outros municípios, igualmente vulneráveis à ação da planta, também condiz com a gravidade dessa disseminação apontada no levantamento epidemiológico de Polack (1990), com a ressalva de que o número de surtos agudos e a ocorrência de 
casos crônicos aumentou demasiadamente (MARÇAL et al., 2002).

Qualquer que seja a estratégia para controle da intoxicação pela samambaia em bovinos criados no Paraná, é imprescindível que se recupere o meio ambiente como um todo, com orientações e planejamento amplo. Erradicar totalmente a planta pela correção da acidez do solo e formação de pastagens, pode contribuir para resolver o problema, mas não atende o reequilíbrio ambiental necessário, já que a Pteridium aquilinum é um vegetal componente da natureza e deve ter sua finalidade na Terra.

\section{Referências}

ALONSO-AMELOT, M.E.; CASTILLO, U.; SMITH, B. L.; LAUREN, D. R.; AMELOT, M. E. A. Bracken ptaquiloside in milk. Nature, London, v.382, n.6592, p.587, 1996.

BARKER, I. K.; VAN DREUMEL, A. A.; PALMER, N. The alimentary system: neoplasia of the esophagus and forestomachs. In: JUBB, K. V.F.; KENNEDY P.C.; PALMER N. (Eds). Pathology of domestic animals. $4^{\text {th }}$ ed. San Diego: Academic Press, 1993. v.2, p.51-52

BASILE, J. R.; GASTE, L.; REIS, A.C.F. Intoxicação aguda de bovinos pela samambaia (Pteridium aquilinum) no estado do Paraná. Revista de Ciências Agrárias, Curitiba, v.3, p.167-170, 1981.

BLOOD, D. C.; HENDERSON, J. A.; RADOSTITS, O. M. Clínica veterinária. 5.ed. São Paulo: Guanabara Koogan, 1979.

BUENO, P. Papilomatose faringeana em bovinos. $O$ Biológico, São Paulo, v.19, n.1, p.8-10,1953.

CAMPO, M. S.; MOAR, M. H.; JARRET, W. F. H.; LAIRD, H. M. A new papillomavirus associated with alimentary cancerin cattle. Nature, London, v.286, n.5769, p.180-182, 1980.

CAMPOS NETO, O.; BARROS, H. M.; BICUDO, P. L. Estudo do carcinoma do trato digestivo superior e da hematúria enzoótica dos bovinos na região de BotucatuSP. Arquivos da Escola de Veterinária da UFMG, Belo Horizonte, v.27, n.2, p.125-139, 1975

CLARKE, E. G. C.; CLARKE, M. D. Veterinary toxicology. Baltimore: Willians \& Wilkins, 1975.

CORREA, M. P. Dicionário de plantas úteis do Brasil e das exóticas cultivadas. Rio de Janeiro: Ministério da Agricultura, 1931. v.2
DOBEREINER, J.; TOKARNIA, C. H.; CANELLA, C. F.C. Ocorrência de hematúria e de carcinomas epidermóides no trato digestivo superior em bovinos no Brasil. Pesquisa Agropecuária Brasileira, Brasília, v.2, p.489-504, 1967.

DURÃO, J. F. C; FERREIRA, M. L.; CABRAL, A. et al. Aspectos anatomopatológicos e clínicos da hematúria enzoótica dos bovinos. Revista Portuguesa de Ciências Veterinárias, Lisboa, v.5, n.1, p.11-20, 1995.

EVANS, I. A.; HOWELL, R. M. Bovine bracken poisoning. Nature, London, v.194, n.4828, p.584-585, 1962.

EVANS, W.C.; EVANS, E.T.R.; HUGHES, L.E. Studies on bracken fern poisoning in cattle. British Veterinary Journal, London, v.110, pt.1, p.295-306,1954.

FENWICK, G. R. Bracken (Pteridium aquilinum) - toxic effects and toxic constituents. Journal of the Science of Food and Agriculture, London, v.46, p.147-173, 1988.

FERREIRA, J.C. V. O Paraná e seus municípios. Maringá : Memória Brasileira, 1996.

FRANÇA, T. N.; TOKARNIA, C.H.; PEIXOTO, P. V. Enfermidades determinadas pelo princípio radiomimético de Pteridium aquilinum (Polypodiaceae). Pesquisa Veterinária Brasileira, Rio de Janeiro, v.22, n.3, p.85-96, 2002.

GIBBONS, W. J. Bracken poisoning. American Veterinary Publician, p.518-520, 1956.

HAGAN, W. A . Bracken poisoning of cattle. Cornell Veterinarian, Ithaca, v.15, p.326-332, 1952.

HAYASHI, T. Aplication of jamshidi's needle to bone narrow biopsy and diagnosis of bracken poisoning in cattle. Journal of the Japan Veterinary Medical Association, Tokyo, v.34, p.206-211, 1981

HIRAYAMA, T. Diet and cancer. Nutrition and Cancer, Mahwah, v.1, p.67-81, 1979.

HIRONO, I.; FUSHIMI, K.; MORI, H.; MIWA, T.; HAGA, M. Comparative carcinogenic activity of in each part of bracken. Journal of National Cancer Institute, Bethesda, v.50, n.5, p.1367-1371, 1973.

HOPKINS, N. C. G. Aetiology of enzootic haematuria. The Veterinary Record, London, v.118, p.715-717, 1986.

JARRET, W. F. H. Transformation of warts to malingancy in alimentary carcinoma in cattle. Bulletin Cancer, Geneve, v.65, n.2, p.191-194, 1978.

LACAZ, S. J. Cistite hemorrágica ou hematúria crônica dos bovídeos. O Biológico, São Paulo, v.20, n.4, p.64-65, 1954.

LORENZI, H. Pteridium aquilinum (L) Kuhn. In:

Plantas daninhas do Brasil: terrestres, aquáticas, tóxicas e medicinais. Nova Odessa, 1982. p.341 
MARÇAL, W. S. Braquiária reduz a intoxicação por samambaia. O Estado de São Paulo, 23 set. 1992. Suplemento Agrícola, p.24.

MARÇAL, W. S. Samambaia em pasto é veneno. Folha de Londrina, Londrina, 24 mar. 1990. Folha Rural, n. 718, p. 13.

MARÇAL, W. S. GASTE, L.; REICHERT NETTO, N. C.; GARGANTINI, M.; FERNANDES, R. P.; MONTEIRO, A.

A. Ocorrência de intoxicação aguda em bovinos pela samambaia (Pteridium aquilinum, L. Kuhn) no norte do Paraná - Brasil. Semina, Londrina, v.22, n.2, p.139-144, jul./dez 2001.

MARÇAL, W. S.; GASTE, L.; REICHERT NETTO, N. C.; MONTEIRO, F. A. Intoxicação aguda pela samambaia (Pteridium aquilinum, L. Kuhn), em bovinos da raça Abeeerden angus. Archives of Veterinary Science, Curitiba, v.7, n.1, p.77-81, 2002.

MARÇAL, W. S.; GASTE, L; BALARIN, M. R. S. Perspectiva terapêutica para a hematúria enzoótica dos bovinos. I - Estudo clínico preliminar. In: CONFERÊNCIA ANUAL DA SOCIEDADE PAULISTA DE MEDICINA VETERINÁRIA, 46., 1991, São Paulo. Anais... São Paulo: SPMV, 1991.p.48.

MARÇAL, W. S; CAMPOS NETO, O. Condições nutricionais favoráveis à toxidez da samambaia nos bovinos. Revista Pecuária de Corte, São Paulo, n.61, p.94-96, nov.1996.

MARÇAL, W.S. A toxidez da samambaia nos bovinos. 2000. Disponível em: <http://www.saudeanimal.com.br/ bovino-samambaia.htm>. Acesso em: 10 ago. 2001.

MAXIE, M. G. The urinary system. Enzootic hematuria. In: JUBB, K. V. F.; KENNEDY, P. C.; PALMER, N. (Eds). Pathology of domestic animals. $4^{\text {th }}$ ed. San Diego: Academic Press. San Diego, 1993. p.534-536

MOURA, J. V. Aberrações cromossômicas em bovinos intoxicados crônica e naturalmente pela samambaia (Pteridium aquilinum). 1989. Dissertação (Mestrado) Instituto de Biociências, Universidade de São Paulo, São Paulo. 1989.

MUELER, S. B.; MADUREIRA, F. R.; ALENCAR FILHO, R. A.; RIBEIRO, L. O. C.; SOUZA, J. A. Tentativa de reprodução experimental da hematúria enzoótica em bovinos pela administração de samambaia. Arquivos do Instituto Biológico, São Paulo, v.42, p.203-212, 1975.

MUSCA, M. S. Histopathological and haematological studies in cows with enzootic haematuria. Revista Romana de Medicina Veterinária, Bucuresti, v.7, n.3, p.241-245, 1997.

NIERO, L.; MARÇAL, W. S., REIS, A.C.F., ACCORSI, E. Surto de intoxicação aguda em bovinos pela ingestão de samambaia (Pteridium aquilinum, L. Kuhn) no norte do Paraná. In: SIMPÓSIO DE ESTAGIÁRIOS DO CCB/UEL, 9. 1991, Londrina. Anais... Londrina : UEL, 1991. p.90

OINONEM, E. The correlation between the size of finish bracken Pteridium aquilinum (L) Kuhn clones and certain periods of site story. Acta Forestalia Fennica, Helsinki, v.83, n.2, p.1-51, 1967.

OLIVEIRA, G. P.; MATSUMOTO, T.; PRIMAVESI, A. C. Ocorrência de intoxicação causada por samambaia (Pteridium aquilinum) na região nordeste do Paraná. Comunicado Técnico Embrapa, São Carlos, n.20, p.1-9, out.1998.

PAGE, C.N. The taxonomy and phitogeography of bracken: a review. Botanical Journal of the Linnean Society, London, v.73, p.1-34, 1976.

PAMUKCU, A. M.; GOKSOY, S. K.; PRICE, J. M. Urinary bladder neoplasms induced by feed bracken fern (Pteris aquilina) to cows. Cancer Research, Philadelphia, v.27, n.1, p.917-924, 1967.

PAMUKCU, A. M.; PRICE, J. M.; BRYAN, G. T. Naturally ocurring and bracken - fern - induced bovine urinary bladder tumors. Veterinary Pathologic, Washington, v.13, p.110-122,1976.

PARKER, W. H. ; McCREA, C. T. Bracken (Pteris aquilina) poisoning of sheep in the Nort York Moors. The Veterinary Record, London, v.77, p.861-866, 1965.

POLACK, E.W. Toxicidade da Pteridium aquilinum no Estado do Paraná. 1990. Dissertação (Mestrado) Universidade Federal do Paraná, Curitiba. 1990.

REICHMANN, C. E. Hematúria enzoótica dos bovinos. São José do Rio Preto, 1975. Palestra proferida.

RIET-CORREA, F; MÉNDEZ, M.C.; SCHILD, A. L. Intoxicação por plantas e micotoxicoses em animais domésticos. Pelotas: Varela, 1993.

ROSENBERGER, G.; HEESCHEN, W. Adlerfarn (Pteris aquilina) - die Ursache des sog. Stallrotes der Rinder (Haematuria vesicalis bovis chronica). Deutsche Tieraerztliche Wochenschrift, Tucson, v.67, n.8, p.201-208, 1960.

SEHNEM, A. Pteridáceas. In: REITZ, P. R. (Ed.). Flora ilustrada catarinense. Itajaí: [s.n.], 1972.

SINGH, A. K; JOSHI, H. C; RAY, S. N. Serum mucoprotein and silical acid in enzootic bovine haematuria. Zentralblatt-feur-Veterinarmedizin, Berlin, v.27 A, n.8, p.678-681, 1980.

SIPPEL, W. L. Bracken fern poisoning. Journal of the American Veterinary Medical Association, Schaumburg, v. 121, p.9-13, 1952. 
SOUZA, M. V.; GRAÇA, D. L. Intoxicação crônica por Pteridium aquilinum em Bovinos. Ciência Rural, Santa Maria, v.23, n.2, p.203-207, 1993.

STOBER, M. Adlefarn (Pteridium aquilinum). In: ROSENBERGER, G. (Ed.). Krankheiten des rindes. Berlin: Paul Parey, 1970. p.1260-1265.

TAYLOR, J. A. The Bracken problem: a global perpective. In: TAYLOR, J. A.; SMITH, R. T. (Eds). Bracken control and management. Sydney: Australian Institute of Agricultural Science, 1989. p.3-19.

TOKARNIA, C. H.; DOBEREINER, J.; CANELLA, C. F. C. Ocorrência de hematúria enzoótica e de carcinomas epidermóides no trato digestivo superior em bovinos no Brasil. II Estudos complementares. Pesquisa Agropecuária Brasileira, Brasília, v.4, p.209-224, 1969.

TOKARNIA, C. H.; DOBEREINER, J.; CANELLA, C. F. C. Ocorrência de intoxicação aguda pela "samambaia" (Pteridium aquilinum) em bovinos no Brasil. Pesquisa Agropecuária Brasileira, Brasília, v.2, p.329-336, 1967.
TOKARNIA, C.H.; DOBEREINER, J.; PEIXOTO, P.V. Plantas tóxicas do Brasil. Rio de Janeiro: Helianthus, 2000.

TOKARNIA, C. H.; DOBEREINER, J.; SILVA, M. F. Plantas tóxicas da Amazônia a bovinos e outros herbívoros. Manaus: INPA, 1979.

TRYON, R. M. A revision of the genus Pteridium. Rhodora, Lawrence, v.43, p.1-67, 1941.

YAMANE, O; HAYASHI, T; SAKU, S. Studies on blood coagulation disorders in domestic animals thrombelastograms of normal cattle and cattle affected with bracken poisoning. Japanese Journal of Veterinary Science, Tokyo, v.37, p. 577-583, 1975. 
